\title{
Syntenic relationships between cucumber (Cucumis sativus L.) and melon (C. melo L.) chromosomes as revealed by comparative genetic mapping
}

Dawei Li ${ }^{1,2}$, Hugo E Cuevas ${ }^{2,3}$, Luming Yang ${ }^{2}$, Yuhong Li ${ }^{1,2}$, Jordi Garcia-Mas ${ }^{4}$, Juan Zalapa ${ }^{2,5}$, Jack E Staub ${ }^{6}$, Feishi Luan ${ }^{7}$, Umesh Reddy ${ }^{8}$, Xiaoming He ${ }^{2,9}$, Zhenhui Gong ${ }^{1}$ and Yiqun Weng ${ }^{2,5^{*}}$

\begin{abstract}
Background: Cucumber, Cucumis sativus L. $(2 n=2 \times=14)$ and melon, C. melo L. $(2 n=2 \times=24)$ are two important vegetable species in the genus Cucumis (family Cucurbitaceae). Both species have an Asian origin that diverged approximately nine million years ago. Cucumber is believed to have evolved from melon through chromosome fusion, but the details of this process are largely unknown. In this study, comparative genetic mapping between cucumber and melon was conducted to examine syntenic relationships of their chromosomes.

Results: Using two melon mapping populations, 154 and 127 cucumber SSR markers were added onto previously reported $\mathrm{F}_{2^{-}}$and RIL-based genetic maps, respectively. A consensus melon linkage map was developed through map integration, which contained 401 co-dominant markers in 12 linkage groups including 199 markers derived from the cucumber genome. Syntenic relationships between melon and cucumber chromosomes were inferred based on associations between markers on the consensus melon map and cucumber draft genome scaffolds. It was determined that cucumber Chromosome 7 was syntenic to melon Chromosome I. Cucumber Chromosomes 2 and 6 each contained genomic regions that were syntenic with melon chromosomes $I I I+\mathrm{V}+\mathrm{XI}$ and $I I I+\mathrm{V} I I+\mathrm{XI}$, respectively. Likewise, cucumber Chromosomes 1, 3, 4, and 5 each was syntenic with genomic regions of two melon chromosomes previously designated as $I+\mathrm{XII}, \mathrm{IV}+\mathrm{VI}, \mathrm{VII}+\mathrm{VIII}$, and IX+X, respectively. However, the marker orders in several syntenic blocks on these consensus linkage maps were not co-linear suggesting that more complicated structural changes beyond simple chromosome fusion events have occurred during the evolution of cucumber.

Conclusions: Comparative mapping conducted herein supported the hypothesis that cucumber chromosomes may be the result of chromosome fusion from a 24-chromosome progenitor species. Except for a possible inversion, cucumber Chromosome 7 has largely remained intact in the past nine million years since its divergence from melon. Meanwhile, many structural changes may have occurred during the evolution of the remaining six cucumber chromosomes. Further characterization of the genomic nature of Cucumis species closely related to cucumber and melon might provide a better understanding of the evolutionary history leading to modern cucumber.
\end{abstract}

Keywords: Cucumber, Melon, Cucumis, Microsatellite, Comparative mapping, Chromosome evolution

\footnotetext{
* Correspondence: Yiqun.Weng@ars.usda.gov

${ }^{2}$ Horticulture Department, University of Wisconsin, Madison, WI 53706, USA

Full list of author information is available at the end of the article
} 


\section{Background}

The genus Cucumis (family Cucurbitaceae) includes two economically important vegetable crop species that are cultivated worldwide: cucumber (C. sativus $\mathrm{L}$., $2 \mathrm{n}=2 \times$ = 14) and melon ( $C$. melo L., $2 \mathrm{n}=2 \times=24)$. The genetic, phylogenetic, and evolutionary relationships of cucumber and melon have been the subject of much research. The genus Cucumis initially contained 32 species that was divided into two subgenera, Melo and Cucumis [1]. While the subgenus Melo is centered in Africa with 30 species including melon (all of which have $2 n=24$ chromosomes), the subgenus Cucumis is of Asian origin and includes the cultivated cucumber $C$. sativus and its wild relative $C$. hystrix Char. $(2 \mathrm{n}=2 \times=$ 24). Although $C$. melo is considered the most morphologically diverse species in Cucumis [1,2], two inter-fertile botanical varieties $(2 \mathrm{n}=2 \times=14)$, the cultivated $C$. sativus var. sativus $\mathrm{L}$. and the wild C. sativus var. hardwickii (Royle) Alef., comprise the primary gene pool of cucumber. This gene pool has a rather narrow genetic base as evidenced in various genetic diversity studies [3-6]. No interspecific hybrids between melon and cucumber have been reported due to their sexual incompatibility [7].

The genus Cucumis has undergone considerable revision in recent years. For instance, molecular phylogenetic studies indicated that the genera such as Cucumella, Mukia, Dicaelospermum, Myrmecosicyos, and Oreosyce possess genetic affinities with Cucumis species resulting in their inclusion in Cucumis in more recent taxonomic treatments [8-10]. The genus Cucumis in the newest treatment contains 52 species, which are grouped into two subgenera: Humifructus (two species, C. humifructus and C. hirsutus) and Cucumis (consisting of the remaining 50 species) $[9,11]$. In addition, both melon and cucumber are believed to be of Asian origin, which were derived from a common ancestor approximately nine million years ago [12].

The genome size of melon (12 chromosome pairs) is estimated to be $454 \mathrm{Mb}$, and cucumber (7 chromosome pairs) has a genome size of $367 \mathrm{Mbp}$ [13]. The evolutionary relationship between melon and cucumber can be investigated through chromosome analysis. In Kirkbride's taxonomic assessment of Cucumis [2], subgenus Cucumis is considered primitive and subgenus Melo was hypothesized to have been derived from it through chromosomal fragmentation [14-16]. In contrast, cytological investigations have also suggested that ancestral species of subgenus Melo gave rise to subgenus Cucumis species via chromosome fusion or non-homologous translocation $[17,18]$. However, Ramachandran and Seshadri [19] argued that the two subgenera are not closely related given differences in geographical distribution and chromosome number, size, organization, and behavior. More recent molecular-based phylogenetic analyses of Cucumis support the hypothesis that the base chromosome number of $x=7$ was achieved by chromosome reduction from $x=12$ progenitor species $[8,10,12]$.

Despite their distinct phylogenetic relationships $[20,21]$, the genomes of melon and cucumber seem to be highly conserved. Cross-species similarities based on molecular marker transferability among cucurbit crops are well documented. Neuhausen [20] first reported affinities among cucurbit species by identifying molecular cross-hybridizations (i.e., signals) using RFLP probes. More recently, Katzir et al. [21] and Danin-Poleg et al. [22] defined specific genomic regions using SSR primer products to reveal considerable sequence homologies between cucumber and melon. Danin-Poleg et al. [23] identified nine SSR markers shared between melon and cucumber and proposed that their cucumber Linkage Group B and melon Linkage Groups E and 2 were syntenic. Since 2000, molecular markers (primarily SSRs) developed from melon have been used routinely in cucumber genetic mapping studies or vice versa [24-37]. The high degree of synteny and conservation between the melon and cucumber genomes has also been demonstrated at the DNA sequence level (micro-synteny). Park et al. [38] and Meyer et al. [39] compared genomic DNA flanking the zucchini yellow mosaic virus resistance locus (zym) in melon and cucumber and detected considerable marker colinearity between those species. Alignment of melon BAC-end and BAC clone (6.7 Mbp) sequences of melon against a cucumber draft genome assembly (line Gy 14) revealed 90\% homology between the compared sequences $[40,41]$. Although transposition activity was found to be low in cucumber, it is comparatively high in melon [41]. Thus, it has been postulated that the genomic size differences between melon and cucumber is due mainly to the expansion of inter-genic regions and proliferation of transposable elements in the melon genome [41]

Recently, whole genome sequencing in cucumber [42] and the availability of large numbers of molecular markers [43] has made it possible to define more clearly the syntenic relationships between cucumber and melon. By alignment of 348 marker sequences mapped in the melon genome onto the 9930 cucumber draft genome, Huang et al. [42] found that there was no substantial rearrangement between cucumber Chromosome 7 and melon Chromosome I. In addition, the majority of cucumber Chromosome 4 corresponded to melon Chromosome VII, and each of the remaining five cucumber chromosomes was collinear to two melon chromosomes [42]. The correspondance between melon and cucumber chromosomes was also observed in a comparative 
mapping study by Fukino et al. [44], who placed 70 cucumber SSR markers on a melon linkage map.

Comparative genetic mapping is useful for revealing syntenic relationships among closely related planted species $[45,46]$. An understanding of syntenic relationships among species facilitates the investigation of genome evolution and dynamics $[47,48]$, and allows for the use of genetic information among related species in gene isolation and molecular tagging experiments [49-51]. Comparative mapping has been used successfully to define syntenic relationships among closely related plant species in the Solanaceae (pepper, tomato, and potato) [52-55], Gramineae grasses [56,57], Fabaceae legumes [47,58-62], Brassicaceae [63], and Rosaceae (Prunun spp) $[64,65]$.

When compared to other crop species, genetic and genomic resources in cucurbit crops have historically been limited. However, this situation is changing rapidly. For instance, the draft genomes of two cucumber inbred lines (North China fresh market type 9930 and North American pickling type Gy14) have been released [42,66] (also Weng et al., unpublished data). A high resolution linkage map and several SSR-based genetic maps have been developed for this species [43,67-69]. In melon, many linkage maps as well as a BAC-based physical map have been constructed [24,27-29,33-37]. In addition, comparative fluorescence in situ hybridization (FISH) mapping in cucumber and melon [70] suggested that centromere repositioning occurred during the evolution of cucumber chromosomes. Several cucumber chromosomes have been anchored using fosmid clones, and karyotypes of cucumber and melon genomes have been developed [71-75].

Previous studies [38-44] have shown that genomic synteny and co-linearity exists between cucumber and melon. This information is, nevertheless, fragmented and incomplete. Thus experiments were designed herein for large-scale comparative genetic mapping of melon and cucumber to identify syntenic blocks using microsatellite markers. To accomplish this objective, two extended linkage maps in melon were constructed using an $F_{2}$ and a RIL population, which were subsequently merged to form a consensus map. Then the scaffolds of the Gy14 and 9930 cucumber draft genomes were associated to markers on both the melon consensus map and a high-resolution cucumber genetic map [43] to define species chromosomes and allow for the detection of syntenic blocks.

\section{Results}

1. Development of an $F_{2}$-based extended melon linkage map using cucumber SSRs

In total, 2,487 SSR markers were used to screen for polymorphisms between the two parental lines, Q3-2-2 and Top Mark of the $F_{2}$ mapping population. Of these, 2,442 were genomic SSRs developed from cucumber, 21 from watermelon, 14 from melon $[28,29,31]$, and 10 were EST-SSRs from other species [29]. Of the 2,442 cucumber SSRs, 1,123 (45.9\%) produced amplicons in melon after PCR, from which 187 (16.7\%) were polymorphic between Top Mark and Q3-2-2. The success in marker transferability for all cucumber SSRs tested was $7.7 \%(187 / 2,442)$. Of the 21 watermelon genomic SSRs that produced amplicons in cucumber (data not presented), seven (33.3\%) produced amplicons in melon, and two were polymorphic $(2 / 21=9.5 \%)$. In total, 196 non-melon polymorphic markers were identified (187 from cucumber, 2 from watermelon, and 7 from other species) and 154 of them were finally placed on the $F_{2}$ genetic map (145 from cucumber, 2 from watermelon and 7 from other species).

Using this $\mathrm{F}_{2}$ mapping population, Cuevas et al. [35] mapped 169 co-dominant markers (154 SSR, 8 CAPS, and 7 SNP) in 13 linkage groups (LG). Genotypic data from the 154 additional cucumber or watermelon markers developed herein were combined with the previously mapped 169 markers for linkage analysis. All 323 codominant markers (308 SSRs, 15 CAPS/SNP) were placed onto this $\mathrm{F}_{2}$-based melon genetic map in 13 LG. Information on LG and map positions is presented in Table S1 (Additional File 1), and their associated statistics are presented in Table 1. Segregation distortion was rare, where only four markers, CU2186, GCM548, SSR05695, and UW085218 significantly deviated from expected 1:2:1 segregation ratio $(P<$ 0.01). Except for Chromosome IV, each LG could be assigned to corresponding chromosomes as defined by Liu et al. [74]. In our analysis, Chromosome IV was split into two linkage groups (4A and 4B) (Table S1) due to an insufficient number of markers. The $\mathrm{F}_{2}$ based map consisted of 13 LG spanning 1,012 cM, with a mean marker interval of $3.1 \mathrm{cM}$, where the largest gap resided in Chromosome IV associated with LG 4A and LG 4B.

\section{Development of a RIL-based extended melon linkage map with cucumber SSRs}

The molecular markers employed for $F_{2}$ mapping were also used to identify polymorphisms between Top Mark and WI 846-1 of the RIL population. Of the 2,403 cucumber SSRs tested, 44.9\% $(1,080)$ produced amplicons in melon, where $11.1 \%(120 / 1080)$ of the SSRs detected polymorphisms between Top Mark and WI 846-1 (5.9\% when all 2,043 cucumber SSRs were considered). Of the 127 polymorphic markers identified herein (i.e., 120 from cucumber, 6 from melon or Arabidopsis, and 1 from watermelon), 89 were placed on the RIL map. 
Table 1 Summary of linkage mapping results for melon (Cucumis melo L.) $F_{2}$ (Top Mark $\times$ Q3-2-2) and RIL (Top Mark $\times$ WI 846-1) mapping populations and a consensus map from $F_{2}$ and RIL map merging

\begin{tabular}{|c|c|c|c|c|c|c|c|c|c|c|c|c|c|}
\hline \multirow[b]{2}{*}{$\underset{\mathrm{a}}{\mathrm{LG}(\mathrm{Chr})}$} & \multicolumn{3}{|l|}{$F_{2}$ Map $^{b}$} & \multirow[b]{2}{*}{$\begin{array}{l}\text { Map } \\
\text { interval }\end{array}$} & \multicolumn{2}{|l|}{ RIL Map } & \multirow[b]{2}{*}{$\begin{array}{l}\text { total } \\
\mathrm{cM}\end{array}$} & \multirow[b]{2}{*}{$\begin{array}{l}\text { Map } \\
\text { interval }\end{array}$} & \multicolumn{3}{|c|}{ Consensus Map ${ }^{b}$} & \multirow[b]{2}{*}{$\begin{array}{l}\text { Map } \\
\text { interval }\end{array}$} & \multirow{2}{*}{$\begin{array}{l}\text { Relative } \\
\text { length }^{c}\end{array}$} \\
\hline & $\begin{array}{l}\text { \# loci } \\
\text { mapped }\end{array}$ & $\begin{array}{l}\text { \# CS } \\
\text { markers }\end{array}$ & $\begin{array}{l}\text { Total } \\
\text { cM }\end{array}$ & & $\begin{array}{l}\text { \# loci } \\
\text { mapped }\end{array}$ & $\begin{array}{l}\text { \# CS } \\
\text { markers }\end{array}$ & & & $\begin{array}{l}\text { \# loci } \\
\text { mapped }\end{array}$ & $\begin{array}{l}\text { \# CS } \\
\text { markers }\end{array}$ & $\begin{array}{l}\text { Total } \\
\text { cM }\end{array}$ & & \\
\hline 1 (I) & 31 & 14 & 108.7 & 3.5 & 32 & 6 & 65.1 & 2.0 & 38 & 17 & 107.3 & 2.8 & 9.55 \\
\hline $2(I I)$ & 25 & 14 & 104.7 & 4.2 & 25 & 9 & 46.2 & 1.8 & 33 & 19 & 105.7 & 3.2 & 7.50 \\
\hline $3(I I I)$ & 22 & 11 & 81.7 & 3.7 & 14 & 6 & 46.0 & 3.3 & 24 & 13 & 81.8 & 3.4 & 8.01 \\
\hline $4(\mathrm{IV})$ & 34 & 16 & 82.3 & 2.4 & 44 & 15 & 159.1 & 3.6 & 50 & 26 & 116.9 & 2.3 & 12.61 \\
\hline $5(V)$ & 24 & 14 & 87.5 & 3.6 & 19 & 8 & 85.3 & 4.5 & 28 & 16 & 58.2 & 2.1 & 8.30 \\
\hline $6(\mathrm{VI})$ & 23 & 10 & 63.8 & 2.8 & 44 & 9 & 73.0 & 1.7 & 25 & 11 & 64.4 & 2.6 & 9.25 \\
\hline $7(\mathrm{VII})$ & 28 & 12 & 91.9 & 3.3 & 37 & 15 & 106.5 & 2.9 & 41 & 21 & 108.0 & 2.6 & 7.50 \\
\hline $8(\mathrm{VIII})$ & 35 & 16 & 87.1 & 2.5 & 21 & 4 & 48.3 & 2.3 & 39 & 17 & 87.2 & 2.2 & 7.25 \\
\hline $9(I X)$ & 24 & 13 & 71.0 & 3.0 & 16 & 4 & 42.7 & 2.7 & 27 & 13 & 71.9 & 2.7 & 6.70 \\
\hline $10(X)$ & 20 & 11 & 54.2 & 2.7 & 23 & 9 & 57.4 & 2.5 & 30 & 17 & 62.5 & 2.1 & 9.41 \\
\hline $11(\mathrm{XI})$ & 36 & 18 & 100.7 & 2.8 & 37 & 11 & 89.7 & 2.4 & 43 & 23 & 87.4 & 2.0 & 6.70 \\
\hline $12(X I I)$ & 21 & 7 & 78.0 & 3.7 & 23 & 3 & 59.8 & 2.6 & 23 & 6 & 77.6 & 3.4 & 7.21 \\
\hline $\begin{array}{l}\text { Sum/ } \\
\text { average }\end{array}$ & 323 & 156 & 1011.6 & 3.1 & 335 & 99 & 879.1 & 2.6 & 401 & 199 & 1029.0 & 2.6 & $n / a$ \\
\hline
\end{tabular}

${ }^{\mathrm{a}} \mathrm{LG}=$ linkage group. $\mathrm{Chr}=$ chromosome

${ }^{\mathrm{b}}$ \# CS markers = number of markers from cucumber that were mapped in each linkage group.

${ }^{c}$ Relative length $=$ length of individual chromosome/total length of all 12 chromosomes $\times 100$ [74]

Using the same melon RIL population, Cuevas et al. [34] mapped 256 marker loci (105 SSR, 11 SNP/CAPS, and 140 AFLP or RAPDs). The two sets of marker data were pooled for linkage analysis using 80 RILs. Ten of these markers could not be assigned to any LG. The resulting linkage map possessed 335 marker loci including 203 codominant (SSR, CAPS, and SNP) and 132 dominant markers (103 RAPDs and 29 AFLPs) in 22 LG with cumulative genetic distances of $879.1 \mathrm{cM}$. The mapping data are presented in Table S2 (Additional File 1) and associated map statistics are shown in Table 1. Based on SSR markers shared in common with previously published melon maps $[29,34,35,76]$, it was possible to relegate the LGs constructed herein to 12 linkage groups (chromosomes).

\section{Development of a consensus melon genetic map through map merging}

The $F_{2}$ and RIL maps developed herein shared 79 markers in common (44 melon, 34 cucumber, and 1 watermelon), and were merged to produce a consensus map using the JoinMap 3.0 program. The 132 dominant AFLP and RAPD markers resident on the RIL map were excluded from map integration because they were deemed ineffective for defining cucumber-melon synteny. These markers tended to clustered on the linkage map, and a number of them showed segregation distortion (data not shown). In contrast to the RIL map, the 323 markers on the $F_{2}$ map were co-dominant and their order was used as the reference during map merging.
The resulting consensus linkage map is presented in Figure 1 and summarized in Table 1. Shared loci (boldface typed) between the $F_{2}$ and RIL maps are given in Table S3 (Additional File 1).

The consensus melon genetic map consisted of 401 co-dominant marker loci positioned in 12 LGs spanning $1,029.0 \mathrm{cM}$ with an average marker interval of $2.6 \mathrm{cM}$. Among the 12 LGs, LG4 (Chromosome IV) had the longest map length $(116.9 \mathrm{cM})$ followed by LG7 (108.0 cM) and LG1 (107.3 cM). In contrast, the length of LG 10 (Chromosome X) was the shortest $(62.5 \mathrm{cM})$. Predictably LG4 possessed the most loci mapped (56) and LG3 (24) the least markers (Table 1). Since marker order of the $\mathrm{F}_{2}$ map was used as the reference during map merging, all loci on the consensus map were colinear with those on the $F_{2}$ map. Moreover, inconsistencies in marker order were rare resulting in substantial colinearity between the RIL map (Table S2) and the consensus map (Table S3, Figure 1).

\section{Identification of syntenic blocks between melon and cucumber chromosomes}

Among the 401 markers present on the consensus melon map, 199 were SSR or CAPS markers developed from cucumber, one from the watermelon, and the remaining 201 were derived from melon. The cucumber Gy14 and 9930 draft genome scaffold locations of these 401 markers were predicted by in silico PCR or BLAST searches of the cucumber draft genome sequences. 


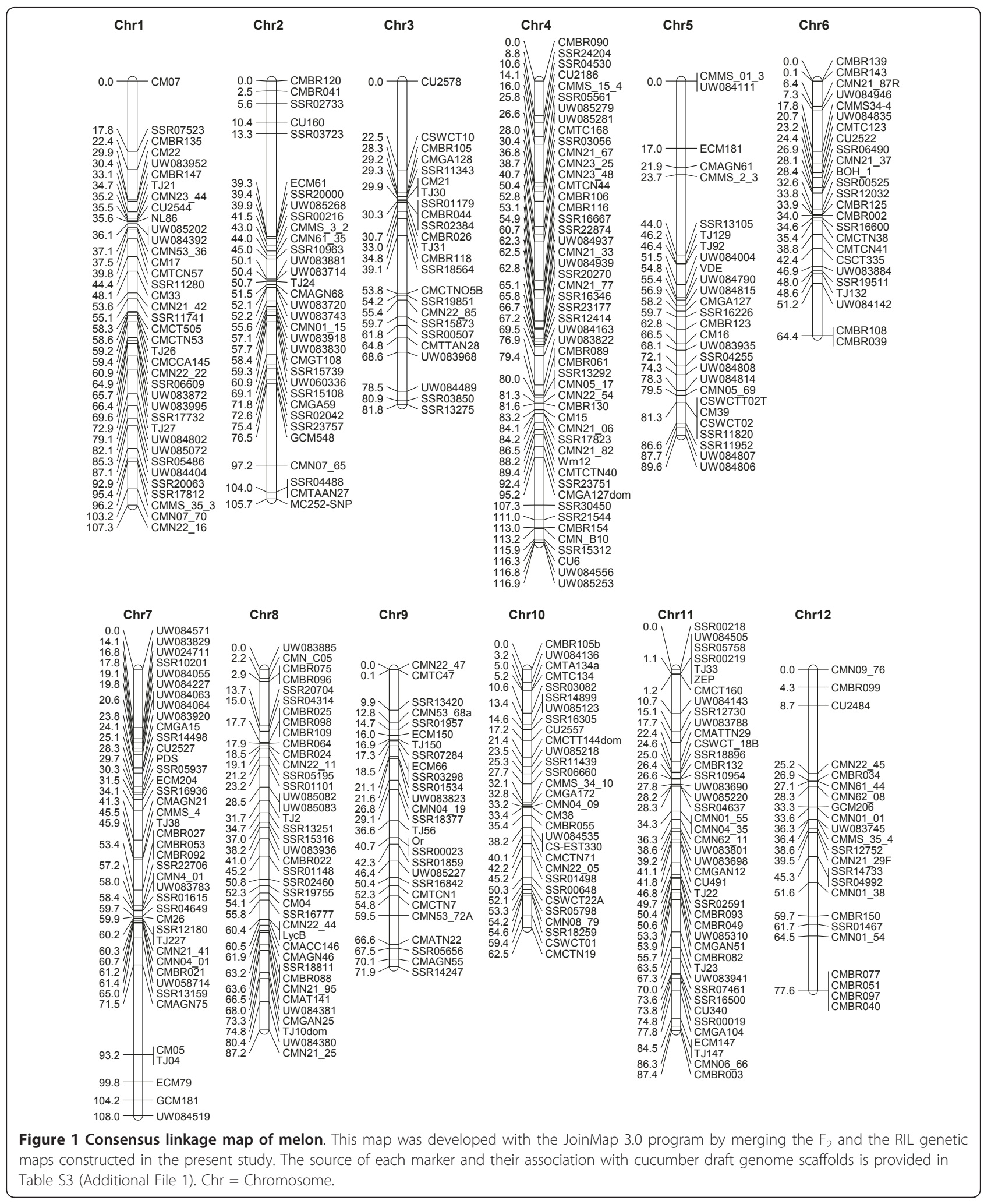


Seventy-four of the 401 markers on the consensus melon map had no in silico PCR products or BLAST hits suggesting that they may be specific to the melon genome. Three markers (CMN53_36, UW084111, and SSR05758) were located in sequences that were annotated as repeated sequences [42], and, therefore, their cucumber scaffold locations were difficult to determine. The remaining 324 markers could be assigned to the Gy14 and 9930 cucumber scaffolds. The scaffold names and physical positions of these markers are presented in Table S3 (Additional File 1).

Once the association of these markers on the melon consensus map with cucumber scaffolds was established, the locations of these cucumber scaffolds in the seven chromosomes of cucumber were deduced from published cucumber genetic maps [43,67-69] (provided in Table S4, Additional File 1). Among the 401 markers placed on the melon consensus map, 79 have been mapped in previous cucumber mapping studies [43,67-69]. Therefore, their locations on cucumber genetic maps could be assigned directly. For markers with associated cucumber scaffold(s), their map locations in the cucumber genome was inferred by other markers derived from the same scaffold, which had been previously placed on cucumber maps (Table S4). However, three markers (UW060336, LycB, and CMCTN7) were located in cucumber scaffolds from which no marker has been mapped. Therefore, their locations in the cucumber genome were unknown.

With molecular markers shared between the melon and cucumber genetic maps or linked by cucumber draft genome scaffolds, syntenic relationships between cucumber and melon chromosomes could be directly inferred. Figure 2 depicts a view of the 12 melon chromosomes consisting of cucumber syntenic blocks (Chromosomes I to XII, where each melon chromosome is portrayed in increasing order of map saturation). Inspection of Figure 2 and Table S3 indicated that melon Chromosome I was syntenic to cucumber Chromosome 7. Likewise, Chromosomes II and XII were syntenic with cucumber Chromosome 1; Chromosomes IV and VI were syntenic with cucumber Chromosome 3; and Chromosomes IX and X were syntenic with cucumber Chromosome 5. Similarly, the three melon chromosomes III, VIII, and XI contained blocks that were syntenic to two cucumber chromosomes, $2+6,4+6$, and 2 +6 , respectively. These melon-cucumber syntenic relationships are summarized in Table 2.

It has been previously hypothesized that cucumber chromosomes evolved from a progenitor species with $2 \mathrm{n}$ $=2 \times=24$ chromosomes through chromosome fusion ([42]; also see Discussion below). Thus, a melon syntenic block view of cucumber chromosomes was developed which is shown in Figure 3. In this view, the

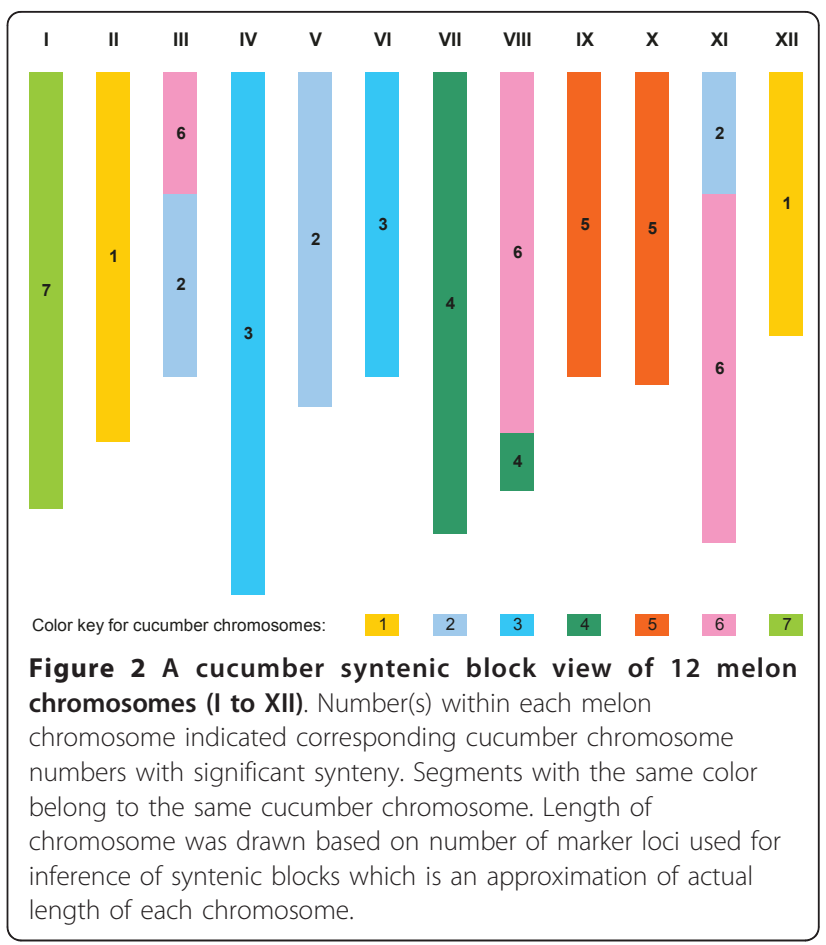

scaffolds in each cucumber chromosome were arranged in the same order as were marker loci on cucumber genetic maps. In most cases, the high resolution genetic map developed by Ren et al. [43] was used as a reference for ordering those scaffolds. In rare instances, however, marker locations did not coincide with those of Ren et al. [43] and, thus, other more recent cucumber genetic maps [67-69] were consulted to infer marker map locations (data not shown).

The arrangement of melon syntenic blocks across the seven cucumber chromosomes indicates that cucumber chromosome evolution is more complex than simple chromosome fusion (Figure 3). For instance, cucumber Chromosome 7 was homoeologous to melon Chromosome I along its entire length. Cucumber Chromosomes 2 and 6 each contained three syntenic blocks detected in melon Chromosomes $\mathrm{V}+\mathrm{XI}+\mathrm{III}$, and $\mathrm{III}+\mathrm{XI}+\mathrm{XIII}$, respectively, and the remaining four cucumber chromosomes $(1,3,4$, and 5$)$ were syntenic with two melon chromosomes but differed in patterns of arrangement of melon syntenic blocks. Cucumber Chromosome 1 was syntenic to melon Chromosome II and XII, whereas cucumber Chromosome 5 was syntenic to melon Chromosome IX and X. In both cases, the syntenic blocks from the two melon chromosomes were arranged alternatively along each cucumber chromosome. In contrast, the syntenic blocks residing in melon Chromosomes VI and IV were in a side-by-side alignment in cucumber Chromosome 3. Lastly, cucumber Chromosome 4 housed syntenic blocks of melon Chromosome VII and 
Table 2 Summary of syntenic relationships between cucumber (Cucumis sativus L.) and melon (C. melo L.) chromosomes

\begin{tabular}{|c|c|c|c|}
\hline \multirow[b]{2}{*}{ Cucumber Chromosomes } & \multicolumn{3}{|c|}{ Corresponding syntenic blocks of melon chromosomes } \\
\hline & This study & Huang et al. 2010 [42] & Fukino et al. 2010 [44] \\
\hline 1 & $\|, X\|$ & $\|, X\|$ & $\|, X\|$ \\
\hline 2 & $I I I, V, X I$ & III, V & III, V \\
\hline 3 & IV, VI & $\mathrm{IV}, \mathrm{VI}$ & $\mathrm{IV}, \mathrm{VI}$ \\
\hline 4 & VIII, VIII & VII & VIII \\
\hline 5 & $I X, X$ & $I X, X$ & $I X, X$ \\
\hline 6 & III, VIII, XI & III, VIII, XI & $\|I I, V I I I, X\|$ \\
\hline 7 & । & I & । \\
\hline Melon chromosomes & \multicolumn{3}{|c|}{ Corresponding syntenic blocks of cucumber chromosomes } \\
\hline I & \multicolumn{3}{|l|}{7} \\
\hline$\|$ & \multicolumn{3}{|l|}{1} \\
\hline III & \multicolumn{3}{|l|}{2,6} \\
\hline IV & \multicolumn{3}{|l|}{3} \\
\hline V & \multicolumn{3}{|l|}{2} \\
\hline $\mathrm{Vl}$ & \multicolumn{3}{|l|}{3} \\
\hline VII & \multicolumn{3}{|l|}{4} \\
\hline VIII & \multicolumn{3}{|l|}{4,6} \\
\hline IX & \multicolumn{3}{|l|}{5} \\
\hline$x$ & \multicolumn{3}{|l|}{5} \\
\hline$X I$ & \multicolumn{3}{|l|}{2,6} \\
\hline$X \|$ & \multicolumn{3}{|l|}{1} \\
\hline
\end{tabular}

VIII, but the syntenic block of melon Chromosome VIII was found to be incorporated into the syntenic block of melon Chromosome VII. Taken collectively, these syntenic patterns were suggestive of a complex history of chromosomal structure changes during cucumber evolution.

\section{Verification of melon-cucumber syntenic relationships} In this study, in silico PCR and BLAST sequence alignment proved useful for inferring the cucumber scaffold location of markers on the melon consensus map (Figures 2 and 3). To verify the syntenic relationships between cucumber and melon chromosomes detected from comparative mapping conducted herein, a similar strategy was used with molecular markers from a melon linkage map developed by Deleu et al. [36]. This genebased melon linkage map consists of 414 marker loci, of which nearly 200 were SNPs developed from melon EST sequences, and all these markers were derived exclusively from the melon genome. The details of this map are shown in Table S5 (Additional File 1). The genomic or EST sequences from which these markers were developed were used in BLAST analysis against the cucumber draft genome assemblies. Of the 414 markers, only 3 $(0.7 \%)$ did not yield either in silico PCR products or BLAST hits in the cucumber draft genomes examined. This contrasted with markers on the consensus melon map (Table S3), where 81 (20.2\%) of 401 (mostly genomic DNA-derived markers) did not produce hits in either Gy14 or 9930 genome assembly. This suggests that the EST sequences examined are highly conserved between these genomes.

The syntenic relationships between melon and cucumber chromosomes inferred from this gene-based melon genetic map are shown in Table S5 (Additional File 1). Although there were no cucumber source markers on this map, melon-cucumber syntenic relationships revealed from the present study (Figures 2 and 3) were confirmed by this independent study [36].

\section{Discussion}

Cross-species transferability and polymorphisms of cucumber SSRs in the melon genome

Nearly 2,400 randomly sampled cucumber genomic SSRs were tested herein for their ability to detect polymorphisms among three melon parental lines used in map construction. The polymorphism level of cross-species transferable cucumber SSRs was $11.1 \%$ between Top Mark and WI 846-1, and 16.9\% between Top Mark and line Q3-2-2, which would be reduced to 5.9 and $7.7 \%$, respectively if all cucumber SSRs tested were considered. This level was appreciably lower than that reported in other studies $[35,37]$ using melon SSRs. For example, of 492 melon SSRs evaluated for map construction by Cuevas et al. [35], 32\% were polymorphic between two melon lines Q3-2-2 and Top Mark. 


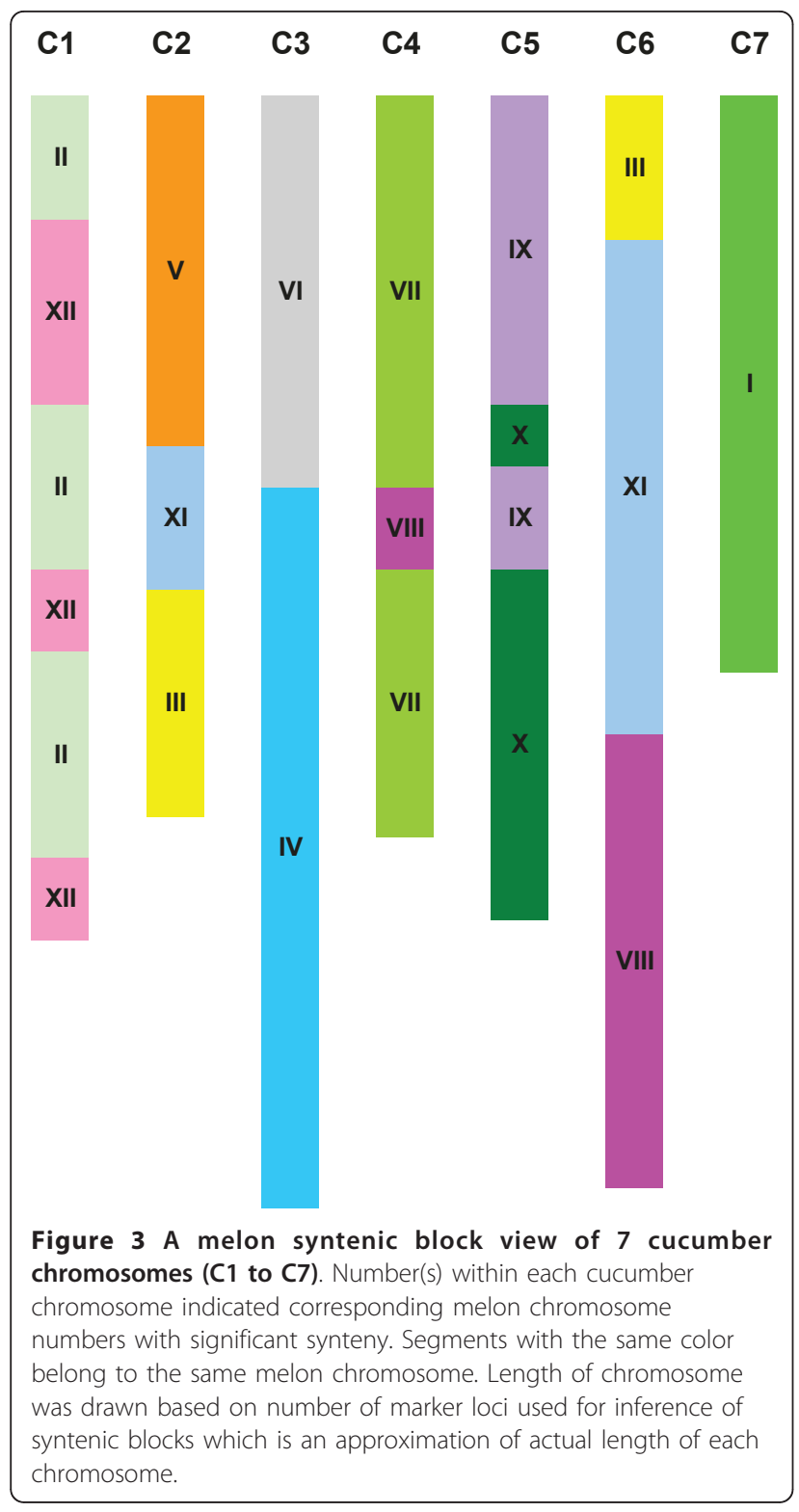

Likewise, the level of polymorphism of melon SSRs between the two melon lines PI 414723 and Dulce used by Harel-Beja et al. [37] was comparatively high (as much as $55 \%$ ).

Such differences in polymorphism level may be attributable to the sources of markers (melon source versus cucumber source), the melon lines used, or the relative genetic distance among the germplasm being evaluated. Two additional factors may also contribute to the low polymorphism level detected by cucumber SSRs. Firstly, unlike melon, which is considered genetically diverse $[2,3]$, cucumber has a narrow genetic base [3-6], and the degree of polymorphism at the whole genome level for randomly chosen SSRs between any two cultivated cucumber genotypes is in general less than 20\% [69]. In the present study, about $45 \%$ of cucumber SSRs examined exhibited cross-species amplification in the melon genome after PCR. This amplification level is similar to that detected by Ritschel et al. [28] who found that $\sim 50 \%$ of the melon SSR markers evaluated produced amplicons when cucumber DNAs were used as templates. González et al. [40] found 54\% of the melon BAC-end sequences under investigation could be aligned to the cucumber genome. It is likely that the melon genomic regions that were amplified by cucumber SSRs represent conserved portions between the cucumber and melon genomes. The genomes of Gy14 and 9930 cucumber lines have been sequenced using the "next generation" sequencing technologies (Roche 454 and Illumina GAII) [42,66], and, therefore, most of the assembled genome sequences may originate from the gene-rich low or single copy DNA fraction in the genome, which are more conserved between closely related species such as melon and cucumber than repetitive DNA sequences $[40,41]$. Therefore, using SSRs developed from highly conserved gene-rich genomic DNA regions of a genome with limited genetic diversity may be an important contributor to the low polymorphism of cucumber SSRs in the melon genome. The second factor, as discussed in Cavagnaro et al. [66], is that melon SSRs used in previous mapping studies (e.g., $[35,37])$ may over-estimate the polymorphism in the genome due to biases created during SSR selection, because of the reiterative selection for longer repeats during development of microsatellite markers. That is, library screening methods for SSR isolation are designed to yield a higher proportion of long SSRs, which are preferentially used for designing primers, which are then typically pre-screened for their relative polymorphism level in potential parental lines. Thus, the most polymorphic loci are selected for further utilization (because there is a positive relationship between SSR length and polymorphism $[66,77,78])$. In this study, the polymorphism level detected between Q3-2-2 and Top Mark (7.7\%) or Top Mark and WI 846-1 (5.9\%), although very low, may reflect the true global polymorphism of cucumber SSRs at the whole melon genome level.

\section{The melon consensus linkage map with cucumber SSRs}

The consensus map developed herein added a considerable number of SSR markers ( 2 times) towards map saturation in melon ( $1<\mathrm{cM}$ between markers). We added 154 and 127 new markers to the previously developed melon $F_{2}$ (from Q-3-2-2 $\times$ Top Mark) and RIL (from Top Mark $\times$ WI 846-1) maps [34,35], respectively. Marker order on the new (Table S1) and the historic $\mathrm{F}_{2}$ maps were almost identical. The RIL map was improved over the historic map [34] (i.e., from 28 LG to 22 LGs), but was still relatively fragmented (i.e., small linkage 
groups), which was likely due to the large number of dominant markers incorporated into the RIL-based map. It is known that dominant markers such as RAPDs or AFLPs tend to be clustered on the linkage maps $[37,67,79-81]$, and for this reason, dominant markers were excluded in map merging for development of the consensus map.

Even though more than the predicted numbers of LGs were present on the $F_{2}$ and RIL maps, the large number of shared marker loci enabled integration of the two maps to produce a consensus melon genetic map with the expected 12 LGs (Table 1, Figure 1). This consensus map contained 401 co-dominant markers including 199 derived from cucumber, and is the first melon map containing such a high number of cucumber-derived markers. The map length of this consensus map was 1,029 $\mathrm{cM}$, which is within the predicted size range of the melon genome (1,000-1,500 cM) [35]. The reliability (quality) of this map can be measured by its colinearity and its relationship with available cucumber scaffolds. Although there were minor discrepancies in marker orders (Tables S1-S3) between markers on the consensus and the RIL-based maps, these maps were largely collinear (Tables S1-S3). The disparities detected between these maps may be, in part, due to varying recombination rates between mapping population (e.g., RIL vs. $F_{2}$ ), relatively small mapping populations (i.e., 80 RIL and $91 \mathrm{~F}_{2}$ individuals) used, and/or genome structural variations (deletion, inversion, or translocation) between populations. With few exceptions, closely linked markers on these melon maps were located in the same cucumber draft genome scaffolds (Table S3).

\section{Synteny between melon and cucumber chromosomes}

Comparative mapping, in silico PCR, and BLAST sequence alignment allowed a comprehensive assessment of syntenic relationships between the cucumber and melon chromosomes (Figures 2 and 3). Among the 401 markers positioned on the melon consensus map, 81 provided no in silico PCR products or BLAST hits in the cucumber genome sequences examined (Table S3). Most of these 81 markers were derived from melon genomic DNA sequences (Table S3), indicating their uniqueness to the melon genome. The genomic distribution of these "no-hit" markers also appears to be nonrandom on the melon consensus map, and in many cases (Chromosomes II, V, VI, VIII, IX, X, XI, and XII), these markers were located at telomeric ends, implying the possibility of rapid evolutionary divergence (Table S3). Such information may allow design of experiments to investigate the nature of these regions in Cucumis chromosome evolution.

Phylogenetic analyses $[8,10,12]$ in Cucumis support an early hypothesis that the base chromosome number $x=7$ in cucumber is derived from a progenitor species with $x=$ $12[17,18]$. Six of the seven cucumber chromosomes may be originated from chromosome fusion of such a progenitor species $[42,44]$. We provide herein additional information regarding the syntenic relationships between cucumber and melon chromosomes indicating that the evolutionary dynamics of cucumber evolution is complex (Table 2, Figure 3). Although we confirmed the early finding $[42,44]$ that cucumber Chromosome 7 was syntenic with melon Chromosome I, we found that the co-linearity of marker loci in the two chromosomes has been broken (Table S3, Additional File 1) suggesting that Chromosome 7 of cultivated cucumber may have undergone certain structural changes since its divergence from an ancestral species (e.g., melon or C. hystrix, see below). The other six chromosomes of cucumber appear to have more complicated evolutionary histories. For instance, both Chromosomes 2 and 6 possess genomic regions that are syntenic to genetic blocks from at least three melon chromosomes $(\mathrm{III}+\mathrm{V}+\mathrm{XI}$, and III+VIII+XI, respectively; Figure 3), suggesting they are derived from more than simple chromosome fusion. Although Chromosomes 1, 3, 4, and 5 each possessed genomic blocks syntenic with those from two melon chromosomes, the arrangements of these blocks differed among chromosomes (Figure 3). Since cucumber Chromosome 3 (longest of the 7 chromosomes) [70,72] appears to be comparatively simple in its syntenic block organization, it is tempting to hypothesize that it originated from simple fusion of melon chromosomes IV and VI. However, close inspection of marker order in cucumber Chromosome 3 and melon Chromosomes IV and VI (Table S3) reveals non-colinearity, which suggests that additional structural changes may have occurred after a hypothetical chromosome fusion event.

Data presented herein provides a rather complicated description of Cucumis species chromosome evolution, making a comprehensive statement regarding chromosome evolution in melon and cucumber difficult at this time. It is apparent that additional information is required regarding the genomic nature of melon, and cucumber, as well as potential 'bridge" species [[12], e.g., C. hystrix) to elucidate more clear evolutionary relationships in this genus. To better understand these relationships a more saturated cucumber genetic map is needed to increase the resolution of cucumber scaffolds for comparative mapping. The cucumber map used herein was developed with 77 RILs from an inter-subspecific cross between cultivated cucumber (C. sativus var. sativus) line Gy14 and the wild C. sativus var. hardwickii line PI 183967 [43]. There were, however, strong recombination suppressions detected during map construction resulting in clustering of molecular markers in several regions of cucumber Chromosomes 4, 5, and 7. Such recombination suppression may, in part, be due to 
structural differences in chromosomes between cultivated and wild cucumbers (Table S3), which, in turn, may have reduced the power of ordering markers and scaffolds. Meanwhile, the whole genome sequencing of melon is near completion (Garcia-Mas et al., manuscript in preparation). This will provide a powerful tool to understand the synteny between the melon and cucumber chromosomes at DNA sequence level.

A wild relative of cucumber, $C$. hystrix $(2 \mathrm{n}=2 \times=24)$, may play the key role in understanding the process of cucumber chromosome evolution. Extensive phylogenetic analyses in Cucumis have indicated that C. hystrix is so far the closest wild relative of cucumber $[8,10,12]$. The lack of genetic affinity between C. hystrix and C. melo, and African species, lends support to the hypothesis that C. hystrix is a progenitor species of $C$. sativus, or that they at least share a common ancestral lineage [82]. $C$. hystrix has the same number of chromosomes as melon, and is sparingly cross-compatible with cucumber, but not melon [83]. A fertile amphidiploid, C. hystivus $(2 \mathrm{n}=4 \times$ $=38$ ) between cucumber and $C$. hystrix, as well as alien addition lines have also been successfully created $[84,85]$. The seven meiotic chromosomes of $C$. sativus are larger than the 12 chromosomes of $C$. hystrix [85]. Fluorescence in situ hybridization of $45 \mathrm{~S}$ rDNA and CsCent 1 repetitve DNA probes to cucumber pachytene chromosomes also suggested that cucumber Chromosomes 1 and 2 may have evolved from fusions of an ancestral karyotype with $2 n=24$ [86]. These findings make C. hystrix the primary resource for testing genetic hypotheses for further characterizing the evolution of modern cucumber.

\section{Conclusions}

This is the first broad-based comparative analysis of synteny between melon and cucumber. The consensus melon linkage map derived herein from two historic maps possesses the largest number of cross-species cucumber molecular markers currently mapped in the melon genome and provides a greater understanding of genomic relationships between these two important Cucumis species. Data support the hypothesis that cucumber chromosomes originate from fusions of chromosomes of an $x=12$ ancestral progenitor. However, many structural changes may have occurred in the evolution of the seven cucumber chromosomes. In depth cytogenetic and molecular investigations of $x=12$ Cucumis species (e.g., melon and C. hystrix) will likely provide further evidence of chromosome evolution in cucumber, melon and related taxons.

\section{Methods}

\section{Plant materials}

Two melon populations were employed to conduct linkage mapping experiments using cucumber microsatellite markers. The first experiment used $91 \mathrm{~F}_{2}$ plants derived from a cross between melon inbred lines Top Mark and Q3-2-2. Top Mark is an andromonoecious U.S. Western Shipping market class melon in Group Cantalupensis [87]. The monoecious line Q3-2-2 does not fall into any common market class, but possesses Group Conomon and Momordica melon morphological fruit characteristics [88]. The second experiment used $80 \mathrm{~F}_{8}$ RIL derived from Top Mark $\times$ WI 846-1 [34]. The monoecious line WI 846-1 was derived through selfing from a three-way cross between a C. melo ssp. agrestis (Naud.) Pangalo germplasm (Cartago, Costa Rica), an Eastern market type breeding line (USDA, ARS, Clemson SC), and a Galia market type breeding line (ARO, Israel) [34]. Both populations were previously used in the mapping of fruit yield- and quality-related components in melon $[34,35,89,90]$.

\section{Molecular marker analysis}

Two sets of SSR markers developed from cucumber whole genome sequences were employed for polymorphism screening and the development of melon linkage maps. The first set included 2,012 SSR markers from the draft genome of cucumber inbred line 9930 [43] and the second set included a collection of 83,689 SSRs developed from the Gy14-derived draft genome [66]. Also employed were 21 watermelon microsatellite markers known to amplify in the cucumber genome (U. Reddy, unpublished data). Information regarding all mapped markers used herein (i.e., primer sequences and their scaffold locations in the Gy14 and 9930 draft genomes) is provided in Table S3 (Additional File 1).

For DNA extraction, unexpanded young leaves from each $\mathrm{F}_{2}$ plant or five plants from each RIL were placed into a $2.0 \mathrm{ml}$ microcentrifuge tube, lyophilized in a freeze dryer, and ground into fine powder in a highthroughput homogenizer (OPS Diagnostics, Lebanon, NJ, USA). Genomic DNA from all samples was extracted using the CTAB method [91].

Each polymerase chain reaction (PCR) contained 25 ng template DNA, $0.5 \mu \mathrm{M}$ each of forward and reverse primers, $0.2 \mathrm{mM}$ dNTP mix, 0.5 unit of Taq DNA polymerase and $1 \times$ PCR buffer (Fermentas, Glen Burnie, MD, USA) in a total volume of $10.0 \mu \mathrm{l}$. A "touch-down" PCR program was employed for all primer sets [92]. The PCR products were size-fractionated in a $9 \%$ polyacrylamide gel. After gel electrophoresis, band patterns were visualized with silver staining, and gel images were taken with a digital camera.

\section{Linkage map construction and map integration}

Previously, 169 and 256 markers loci were positioned, respectively, on Q3-2-2 × Top Mark $F_{2}$ and WI 846-1× Top Mark melon RIL linkage maps [34,35]. Genotypic 
marker data from previous mapping studies and the present study in each population were combined for linkage analysis. For each marker, Chi-square analysis was performed to test goodness-of-fit to expected 1:2:1 segregation ratio for the $F_{2}$ population and 1:1 ratio for the RIL population (significance declared at $P<0.01$ ). Linkage analysis was then performed with JoinMap 3.0 with three rounds of mapping to build the map, and LG were established at a LOD threshold of 4.0 with the Kosambi function.

Seventy-nine markers were shared in common between the $F_{2}$ and the RIL maps. A consensus melon map was developed by merging the two maps according to Cuevas et al. [35]. Common markers having the same recombination fraction (rf) among different populations are required for use as anchor makers during map merging [93]. Therefore, heterogeneity test was conducted for these common markers using JoinMap algorithms to determine recombination fractions in both populations (RIL and $\mathrm{F}_{2}$ ). Common markers with different recombination fraction $(P<0.05)$ were excluded from map merging experiments. All AFLP and RAPD markers present on the RIL-based map were also excluded from map integration given their inability to provide appropriate information for assessment of syntenic relationships. Subsequently, these maps ( $F_{2}$ and RIL) were merged using JoinMap $3.0(\mathrm{LOD}=2.0 ; \mathrm{rf}=0.35-0.50)$ by employing the "fixed order" option according to Qi et al. [94] using the marker order present on the $F_{2}$ map as the reference. This option allowed for the definition of fixed order marker subsets based on marker order in the $\mathrm{F}_{2}$ linkage groups.

The numbering conventions for melon linkage groups and their respective chromosome assignment followed Liu et al. [74], which is consistent with the nomenclature established by the melon research community ([76], also see http://www.icugi.org/). To avoid confusion, cucumber chromosomes were named using Arabic numbers ( 1 through 7$)$, whereas the Roman numerals I to XII were used to indicate melon Chromosomes 1 to 12 , respectively.

\section{Inference of syntenic relationships between the melon and cucumber genomes}

The melon consensus linkage map (401 marker loci) was used to infer syntenic relationships between melon and cucumber chromosomes. The map/chromosomal locations of these markers in the cucumber genome were inferred from procedures given below.

Initially, four SSR-based cucumber genetic maps [43,67-69] were used as a primary reference to determine the chromosomal locations of mapped loci including a high-resolution genetic map (with 995 SSR loci) [43]. These maps contained 1,244 unique SSR or SCAR marker loci distributed in seven cucumber chromosomes. The associated scaffold locations of the majority of these markers in the 9930 or Gy14 draft genome were known [66]. The map locations as well as their chromosomal assignment and associated scaffolds in the 9930 and Gy14 draft genomes of the 1,244 mapped loci are summarized in Table S4 (Additional File 1).

Of the 401 markers positioned on the melon consensus map, 199 originated from cucumber, of which 79 were present on different cucumber genetic maps [43,67-69]. Therefore, the cucumber scaffolds associated with these 79 markers were known. For other markers, an in silico PCR (virtual PCR) strategy [66] was used to deduce their position on the cucumber scaffold of the Gy14 and 9930 draft genome assemblies. For each marker, the output of in silico PCR included the scaffold name, nucleotide positions of left and right primer binding sites, and the sequence and expected size of virtual PCR product. The information was generated and recorded for both 9930 and Gy14 draft genomes and is summarized in Table S3 (melon consensus map) and Table S4 (cucumber linkage maps). In cases where no or multiple in silico PCR products were available, the marker was labeled 'no hit' or 'multi-copy', respectively (Tables S3-S5).

Many markers mapped on the melon consensus map were developed from EST or gene regions (e.g., ESTSSR, or EST-SNP, or genes). In this case, the source DNA sequences were used to perform a BLAST search against the draft genome to find their (marker) scaffold locations. Most of the sequences examined were extracted from the s (http://www.ncbi.nih.gov/), the International Cucurbit Genome Initiative (http://www. icugi.org/), and the MELOGEN (http://www.melogen. upv.es/) databases. Cuevas et al. [34,35] mapped six melon genes in the carotenoid pathway which included genes for the phytoene synthase $(P S)$, beta-carotene hydroxylase-1 $(B O H-1)$, lycopene cyclase $(L y c B)$, zeaxanthin epoxidase $(Z E P)$, phytoene desaturase $(P D S)$, violaxanthin de-epoxidase $(V D E)$, and the orange-related gene $(\mathrm{Or})$. These gene sequences were also employed in BLAST search against the cucumber draft genomes to identify the scaffold locations of their homologous sequences.

Once a marker was assigned to the cucumber draft genome scaffold, its map location was inferred in two ways. Firstly, 79 of the 401 markers had already been mapped in cucumber chromosomes, and they could be directly assigned to specific chromosomal location(s) of the cucumber genome. Secondly, if a marker had not been mapped in cucumber but the cucumber scaffold possessed markers that have been mapped in the cucumber genome, then that marker was assigned to the same location as those markers. 


\section{Verification of melon-cucumber syntenic relationships} A melon genetic map developed by Deleu et al. [36] was used to verify the syntenic relationships between melon and cucumber chromosomes identified by this study. It was selected because it contained 414 markers in 12 LGs, of which nearly half were gene-based SNPs. All the 414 markers were developed exclusively from the melon genome. Genomic or EST sequences from which these markers were developed were downloaded from databases located at MELOGEN (http://www.melogen.upv. es/), GenBank (http://www.ncbi.nih.gov/) or at ICUGI (http://www.icugi.org/) websites. The majority of these markers could be mapped onto cucumber scaffolds using both in silico PCR and BLAST sequence alignment. All information for molecular markers on this consensus melon genetic map is provided in Table S5 (Additional File 1).

\section{Additional material}

Additional file 1: supplemental data file including 5 supplemental MS Excel tables (Table S1 to Table S5). Table S1. Melon (Cucumis melo L.) linkage map developed from the Q3-2-2 $\times$ Top Mark $F_{2}$ mapping population. LG 1 to 12 corresponded to melon Chromosomes I to XII, respectively. Table S2. Linkage map of melon (Cucumis melo L.) developed from a RIL mapping population between WI 846-1 and Top Mark. LG 1 to 12 corresponded to melon Chromosomes I to XII, respectively. Table S3. The melon (Cucumis melo L.) consensus map developed from map integration of the $F_{2}(\mathrm{Q} 3-2-2 \times$ Top Mark) and RIL (WI 846-1 $\times$ Top Mark) linkage maps, and syntenic relationships of cucumber (C. sativus L.) and melon chromosomes. Table S4. Molecular markers mapped in cucumber (Cucumis sativus L.) and their associated scaffolds in the Gy14 and 9930 draft genomes. The map positions of these scaffolds on cucumber maps were used to infer syntenic blocks between melon (C. melo L.) and cucumber chromosomes. Table S5. Cucumber-melon chromosome syntenic relationships inferred from the EST-based melon linkage map by Deleu et al. [36]. Primer sequences of highlighted markers were not presented in Deleu et al. [36]

\section{Abbreviations}

AFLP: amplified fragment length polymorphism; BLAST: basic local alignment search tool; CAPS: cleavaged amplified polymorphic sequence; EST: expressed sequence tag; FISH: fluorescence in situ hybridization; Mbp: million base pairs; LG: linkage groups; PCR: polymerase chain reaction; RAPD: random amplified polymorphic DNA; QTL: quantitative trait loci; RIL: recombinant inbred line; SCAR: sequence characterized amplified region; SNP: single nucleotide polymorphism; SSR: simple sequence repeats.

\section{Acknowledgements}

The authors thank Linda Crubaugh for technical help. This research was supported by U.S. Department of Agriculture-Agriculture Research Service Current Research Information System (CRIS) project no. 3655-21000-037-00D. Feishi Luan's work was partially supported by the '948 Project' of the Agriculture Ministry of China (2010-S22).

\section{Author details}

'Horticulture College, Northwest A \& F University, Yangling 712100, China. ${ }^{2}$ Horticulture Department, University of Wisconsin, Madison, WI 53706, USA. ${ }^{3}$ USDA ARS Tropical Agriculture Research Station, Mayaguez, P.R. 00680, Puerto Rico. ${ }^{4}$ IRTA, Center for Research in Agricultural Genomics CSIC-IRTAUAB, Campus UAB, Edifici CRAG, 08193 Bellaterra (Barcelona), Spain. ${ }^{5}$ USDA ARS Vegetable Crops Research Unit, Horticulture Department, University of
Wisconsin, Madison, WI 53706, USA. 'USDA-ARS, Forage \& Range Research Laboratory, Utah State University, Logan, UT 84322 USA. ${ }^{7}$ Horticulture College, Northeast Agricultural University, Harbin, 150030, China. ${ }^{8}$ Department of Biology, West Virginia State University Institute, WV 25112, USA. 'Vegetable Research Institute, Guangdong Academy of Agricultural Sciences, Guangzhou 510640, China.

\section{Authors' contributions}

$D L$ performed the majority of the experiments. YW conceived the study, designed the experiments, analyzed the data and wrote the manuscript along with editing and suggestions by JES. HC, JZ, and JES developed the melon populations and initial $F_{2}$ and RIL melon genetic maps used as backbones for the consensus map. $L Y, Y L$ and $X H$ conducted linkage mapping in cucumber. JG-M developed the EST-based melon linkage map. UR developed watermelon SSRs and conducted polymorphisms screening of melon parental lines. FL screened additional melon SSRs for polymorphism between parental lines. All authors read and approved the final manuscript.

Received: 16 June 2011 Accepted: 5 August 2011

Published: 5 August 2011

\section{References}

1. Kirkbride JH: Biosystematic monograph of the genus Cucumis (Cucurbitaceae). Boone, NC: Parkway Publishers; 1993, (1993).

2. Whitaker TW, Davis GN: Cucurbits - botany, cultivation, utilization. New York: Interscience Publishers; 1962.

3. Knerr LD, Staub JE, Holder DJ, May BP: Genetic diversity in Cucumis sativus L. assessed by variation at 18 allozyme coding loci. Theor Appl Genet 1989, 78:119-128.

4. Kennard WC, Poetter K, Dijkhuizen A, Meglic V, Staub J, Havey M: Linkages among RFLP, RAPD, isozyme, disease resistance, and morphological markers in narrow and wide crosses of cucumber. Theor Appl Genet 1994, 89:42-48.

5. Dijkhuizen A, Kennard WC, Havey MJ, Staub JE: RFLP variation and genetic relationships in cultivated cucumber. Euphytica 1996, 90:9-89.

6. Meglic V, Staub JE: Inheritance and linkage relationships of allozyme and morphological loci in cucumber (Cucumis sativus L.). Theor Appl Genet 1996, 92:865-872.

7. Robinson RW, Decker-Walters DS: Cucurbits. Crop Production Science in Horticulture \# 6. New York: Cab International; 1997.

8. Ghebretinsae AG, Thulin M, Barber JC: Relationships of cucumbers and melons unraveled: molecular phylogenetics of Cucumis and related genera (Benincaseae, Cucurbitaceae). Am J Bot 2007, 94:1256-1266.

9. Ghebretinsae AG, Thulin M, Barber JC: Nomenclatural Changes in Cucumis (Cucurbitaceae). Novon 2007, 17:176-178.

10. Renner SS, Schaefer H, Kocyan A: Phylogenetics of Cucumis (Cucurbitaceae): cucumber (C. sativus) belongs in an Asian/Australian clade far from melon (C. melo). BMC Evol Biol 2007, 7:58.

11. Schaefer H: Cucumis (Cucurbitaceae) must include Cucumella, Dicoelospermum, Mukia, Myrmecosicyos, and Oreosyce: a recircumscription based on nuclear and plastid DNA data. BLUMEA 2008, 52:165-177.

12. Sebastian P, Schaefer H, Telford IR, Renner SS: Phylogenetic relationships among domesticated and wild species of Cucumis (Cucurbitaceae): The sister species of melon is from Australia. Proc Natl Acad Sci 2010, 107:14269-14273.

13. Arumanagathan K, Earle ED: Nuclear DNA content of some important plant species. Plant Mol Biol Rep 1991, 9:208-218.

14. Whittaker TW: Cytological and phylogenetical studies in the Cucurbitaceae. Botanical Gazette (Crawfordsville) 1933, 94:780-790.

15. Ayyngar KR: Taxonomy of Cucurbitaceae. Bull Nat Inst Sci India 1967, 34:380-396.

16. Bhaduri PN, Bose PC: Cyto-genetical investigations in some common cucurbits, with special reference to fragmentation of chromosomes as physical basis of speciation. J Genet 48:237-256.

17. Trivedi RN, Roy RP: Cytological studies in Cucumis and Citrullus. Cytologia 1970, 35:561-569.

18. Singh AK: Cytogenetics and evolution in the Cucurbitaceae. In Biology and utilization of the Cucurbitaceae, 10-28. Edited by: Bates DM, Robinson RW, Jeffrey C. Cornell University Press, Ithaca, New York, USA; 1990:. 
19. Ramachandran C, Seshadri VS: Cytological analysis of the genome of cucumber (Cucumis sativus L.) and muskmelon (C. melo L). Z Pflanzenzuecht 1986, 96:25-38.

20. Neuhausen SL: Evaluation of restriction fragment length polymorphism in Cucumis melo. Theor Appl Genet 1992, 83:379-384.

21. Katzir N, Danin-Poleg Y, Tzori G, Karchi Z, Lavi U, Cregan PB: Length polymorphism and homologies of microsatellites in several Cucurbitaceae species. Theor Appl Genet 1996, 93:1282-1290.

22. Danin-Poleg Y, Reis N, Tzuri G, Katzir : Development and characterization of microsatellite markers in Cucumis. Theor Appl Genet 2001, 102:61-72.

23. Danin-Poleg Y, Reis N, Baudracco-Arnas S, Pitrat M, Staub JE, Oliver M, Arus $P$, deVicente CM, Katzir N: Simple sequence repeats in Cucumis mapping and map merging. Genome 2000, 43:963-974.

24. Silberstein L, Kovalski I, Brotman Y, Perin C, Dogimont C, Pitrat M, Klingler J, Thompson G, Portnoy V, Katzir N, Perl-Treves R: Linkage map of Cucumis melo including phenotypic traits and sequence-characterized genes. Genome 2003, 46:761-773.

25. Chiba N, Suwabe K, Nunome T, Hirai M: Development of microsatellite markers in melon (Cucumis melo L.) and applications to major cucurbit crops. Breed Sci 2003, 53:21-27.

26. Fazio G, Staub JE, Stevens MR: Genetic mapping and QTL analysis of horticultural traits in cucumber (Cucumis sativus L.) using recombinant inbred lines. Theor Appl Genet 2003, 107:864-874.

27. Monforte AJ, Oliver M, Gonzalo MJ, Alvarez JM, Dolcet-Sanjuan R, Arus P: Identification of quantitative trait loci involved in fruit quality traits in melon (Cucumis melo L.). Theor Appl Genet 2004, 108:750-758.

28. Ritschel PS, Lins TCL, Tristan RL, Buso GSC, Buso JA, Ferreira ME: Development of microsatellite markers from an enriched genomic library for genetic analysis of melon (Cucumis melo L.). BMC Plant Biol 2004, 4:1-14.

29. Gonzalo MJ, Oliver M, Garcia-Mas J, Monforte AJ, Dolcet-Sanjuan R, Katzir N, Arus $\mathrm{P}$, Monforte A: Simple-sequence repeat markers used in merging linkage maps of melon (Cucumis melo L.). Theor Appl Genet 2005, 110:802-811.

30. Kong Q, Xiang C, Yu Z: Development of EST-SSR in Cucumis sativus from sequence database. Mol Ecol Notes 2006, 6:1234-1236.

31. Kong Q, Xiang C, Yu Z, Zhang Z, Liu F, Peng C, Peng X: Mining and charactering microsatellites in Cucumis melo expressed sequence tags from sequence database. Mol Ecol Notes 2007, 7:281-283.

32. Fukino $N$, Yoshioka $Y$, Kubo N, Hirai M, Sugiyama M, Sakata $Y$, Matsumoto $S$ : Development of 101 novel SSR markers and construction of an SSRbased genetic linkage map in cucumber (Cucumis sativus L.). Breed SCi 2008, 58:475-483.

33. Fernandez-Silva I, Eduardo I, Blanca J, Esteras C, Pico B, Nuez F, Arus P, Garcia-Mas J, Monforte AJ: Bin mapping of genomic and EST-derived SSRs in melon (Cucumis melo L.). Theor Appl Genet 2008, 118:139-150.

34. Cuevas HE, Staub JE, Simon PW, Zalapa JE, McCreight JD: Mapping of genetic loci that regulate quantity of beta-carotene in fruit of US Western Shipping melon (Cucumis melo L.). Theor Appl Genet 2008, 117:1345-1359.

35. Cuevas HE, Staub JE, Simon PW, Zalapa JE: A consensus linkage map identifies genomic regions controlling fruit maturity and beta-caroteneassociated flesh color in melon (Cucumis melo L.). Theor Appl Genet 2009, 119:741-756.

36. Deleu W, Esteras C, Roig C, Gonzalez-To M, Fernandez-Silva I, GonzalezIbeas D, Blanca J, Aranda MA, Arus P, Nuez F, Monforte AJ, Picó MB, GarciaMas J: A set of EST-SNPs for map saturation and cultivar identification in melon. BMC Plant Biol 2009, 9:90.

37. Harel-Beja R, Tzuri G, Portnoy V, Lotan-Pompan M, Lev S, Cohen S, Dai N, Yeselson L, Meir A, Libhaber $S E$, et al: A genetic map of melon highly enriched with fruit quality QTL and EST markers, including sugar and carotenoid metabolism genes. Theor Appl Genet 2010, 121:511-533.

38. Park Y, Katzir N, Brotman Y, King J, Bertrand F, Havey M: Comparative mapping of ZYMV resistances in cucumber (Cucumis sativus L.) and melon (Cucumis melo L.). Theor Appl Genet 2004, 109:707-712.

39. Meyer JDF, Deleu W, Garcia-Mas J, Havey MJ: Construction of a fosmid library of cucumber (Cucumis sativus) and comparative analyses of the elF4E and elF(iso)4E regions from cucumber and melon (Cucumis melo). Mol Genet Genomics 2008, 279:473-480.
40. González VM, Rodríguez-Moreno L, Centeno E, Benjak A, Garcia-Mas J, Puigdomènech P, Aranda MA: Genome-wide BAC-end sequencing of Cucumis melo using two BAC libraries. BMC Genomics 2010, 11:618.

41. González VM, Benjak A, Hénaff EM, Mir G, Casacuberta JM, Garcia-Mas J, Puigdomènech P: Sequencing of $6.7 \mathrm{Mb}$ of the melon genome using a BAC pooling strategy. BMC Plant Biol 2010, 10:246.

42. Huang S, Li R, Zhang Z, Li L, Gu X, Fan W, Lucas WJ, Wang X, Xie B, Ni P, Ren $Y$, Zhu H, et al: The genome of the cucumber, Cucumis sativus L. Nat Genet 2009, 41:1275-1281.

43. Ren Y, Zhang ZH, Liu JH, Staub JE, Han YH, Cheng ZC, Li XF, Lu JY, Miao H, Kang HX, Xie BY, Gu XF, Wang XW, Du YC, Jin WW, Huang SW: An integrated genetic and cytogenetic map of the cucumber genome. PLoS One 2009, 4:e5795.

44. Fukino N, Yoshioka Y, Sakata Y, Matsumoto S: Construction of an intervarietal genetic map of cucumber and its comparison with the melon genetic map. In Cucurbitaceae 2010 Proc. Edited by: Thies JA, Kousik S, Levi A. Am Soc Hort Sci, Alexandria, VA, USA; 2010:22-25.

45. Keller $B$, Feuillet $C$ : Colinearity and gene density in grass genomes. Trends Plant Sci 2000, 5:246-251.

46. Paterson A, Bowers J, Burow M, Draye X, Eisik C, Jiang C, Katsar C, Land T, Lin $Y$, Ing R, Wright R: Comparative genomics of plant chromosomes. Plant Cell 2000, 12:1523-1539.

47. Mudge J, Cannon SB, Kalo P, Oldroyd GE, Roe BA, Town CD, Young ND: Highly syntenic regions in the genomes of soybean, Medicago truncatula, and Arabidopsis thaliana. BMC Plant Biol 2005, 5:15.

48. Tang H, Bowers JE, Wang X, Ming R, Maqsudul Alam, Paterson AH: Synteny and collinearity in plant genomes. Science 2008, 320:486-488.

49. Chen M, SanMiguel P, Bennetzen JL: Sequence organization and conservation in sh2/a1-homologous regions of sorghum and rice. Genetics 1998, 148:435-443.

50. Ramakrishna W, Bennetzen $\mathrm{J}$ : Genomic colinearity as a tool for plant gene isolation. Methods Mol Biol 2003, 236:109-122.

51. Nieto C, Morales M, Orjeda G, Clepet C, Monfort A, Sturbois B, Puigdomenech P, Pitrat M, Caboche M, Dogimont C, Garcia-Mas J, Aranda M, Bendahmane A: An elF4E allele confers resistance to an uncapped and non-polyadenylated RNA virus in melon. Plant J 2006, 48:452-462.

52. Bonierbale MW, Plaisted RL, Tanksley SD: RFLP maps based on a common set of clones reveal modes of chromosomal evolution in potato and tomato. Genetics 1988, 120:1095-1103.

53. Tanksley SD, Ganal MW, Prince JP, de Vicente MC, Bonierbale MW, Broun P, Fulton TM, Giovannoni JJ, et al: High density molecular linkage maps of the tomato and potato genomes. Genetics 1992, 132:1141-1160.

54. Park M, Jo SH, Kwon JK, Park J, Ahn JH, Kim S, Lee YH, Yang TJ, Hur CG, Kang BC, Kim SD, Choi D: Comparative analysis of pepper and tomato reveals euchromatin expansion of pepper genome caused by differential accumulation of Ty3/Gypsy-like elements. BMC Genomics 2011, 12:85.

55. Wu FN, Tanksley SD: Chromosomal evolution in the plant family Solanaceae. BMC Genomics 2010, 11:182.

56. Ahn S, Tanksley S: Comparative linkage maps of rice and maize genomes. Proc Natl Acad Sci 1993, 90:7980-7984.

57. Gale MD, Devos KM: Comparative genetics in the grasses. Proc Natl Acad Sci 1998, 95:1971-1974.

58. Kalo P, Seres A, Taylor SA, Jakab J, Kevei Z, Kereszt A, Endre G, Ellis TH, Kiss GB: Comparative mapping between Medicago sativa and Pisum sativum. Mol Genet Genomics 2004, 272:235-246.

59. Yan HH, Mudge J, Kim DJ, Shoemaker RC, Cook DR, Young ND: Comparative physical mapping reveals features of microsynteny between Glycine max, Medicago truncatula, and Arabidopsis thaliana. Genome 2004, 47:141-55.

60. Cannon SB, Sterck L, Rombauts S, Sato S, Cheung F, Gouzy J, Wang X, et al: Legume genome evolution viewed through the Medicago truncatula and Lotus japonicus genomes. Proc Natl Acad Sci 2006, 103:14959-14964.

61. Phan HT, Ellwood SR, Hane JK, Ford R, Materne M, Oliver RP: Extensive macrosynteny between Medicago truncatula and Lens culinaris ssp. culinaris. Theor Appl Genet 2007, 114:549-558.

62. McClean PE, Mamidi S, McConnell M, Chikara S, Lee R: Synteny mapping between common bean and soybean reveals extensive blocks of shared loci. BMC Genomics 2010, 11:184. 
63. Wang J, Lydiate DJ, Parkin IAP, Falentin C, Delourme R, Carion PWC, King GJ: Integration of linkage maps for the amphidiploid Brassica napus and comparative mapping with Arabidopsis and Brassica rapa. BMC Genomics 2011, 12:101.

64. Dirlewanger E, Graziano E, Joobeur T, Garriga-Calderé F, Cosson P, Howad W, Arús P: Comparative mapping and marker-assisted selection in Rosaceae fruit crops. Pro Natl Acad Sci 2004, 101:9891-9896.

65. Jung S, Jiwan D, Cho I, Lee T, Abbott A, Sosinski B, Main D: Synteny of Prunus and other model plant species. BMC Genomics 2009, 10:76.

66. Cavagnaro PF, Senalik DA, Yang LM, Simon PW, Harkins TT, Kodira CD, Huang SW, Weng Y: Genome-wide characterization of simple sequence repeats in cucumber (Cucumis sativus L.). BMC Genomics 2010, 11:569.

67. Weng $Y$, Johnson S, Staub JE, Huang SW: An extended microsatellite genetic map of cucumber, Cucumis sativus L. HortScience 2010, 45:880-886.

68. Miao H, Zhang SP, Wang XW, Zhang ZH, Li M, Mu SQ, Cheng ZC, Zhang RW, Huang SW, Xie BY, Fang ZY, Zhang ZX, Weng Y, Gu XF: A linkage map of cultivated cucumber (Cucumis sativus L.) with 248 microsatellite marker loci and seven genes for horticulturally important traits. Euphytica 2011.

69. Li YH, Pathak M, Yang LM, Li DW, He XM, Weng Y: Fine genetic mapping of compact growth habit in cucumber. Theor Appl Genet

70. Han YH, Zhang ZH, Liu CX, Liu JH, Huang SW, Jiang JM, Jin WW: Centromere repositioning in cucurbit species: Implication of the genomic impact from centromere activation and inactivation. Proc Natl Acad Sci 2009, 106:14937-14941.

71. Koo DH, Hur Y, Jin DC, Bang JW: Karyotype analysis of a Korean cucumber cultivar (Cucumis sativus L. Cv. Winter Long) using C-banding and bicolor fluorescence in situ hybridization. Mol Cells 2002, 13:413-418.

72. Koo DH, Choi HW, Cho J, Hur Y, Bang JW: A high-resolution karyotype of cucumber (Cucumis sativus L. 'Winter Long') revealed by C-banding, pachytene analysis, and RAPD-aided fluorescence in situ hybridization. Genome 2005, 48:534-540.

73. Han YH, Zhang ZH, Liu JH, Lu JY, Huang SW, Jin WW: Distribution of the tandem repeat sequences and karyotyping in cucumber (Cucumis sativus L.) by fluorescence in situ hybridization. Cytogenet Genome Res 2008, 122:80-88.

74. Liu C, Liu J, Li H, Zhang Z, Han Y, Huang S, Jin W: Karyotyping in melon (Cucumis melo L.) by cross-species fosmid fluorescence in situ hybridization. Cytogenet Genome Res 2010, 29:241-249.

75. Han YH, Zhang ZH, Huang SW, Jin WW: An integrated molecular cytogenetic map of Cucumis sativus L. chromosome 2. BMC Genetics 2011, 12:18.

76. Perin C, Hagen LS, De Conto V, Katzir N, Danin-Poleg Y, Portnoy V, Baudracco-Arnas S, Chadoeuf J, Dogimont C, Pitrat M: A reference map of Cucumis melo based on two recombinant inbred line populations. Theor Appl Genet 2002, 104:1017-1034.

77. Weber J: Informativeness of human (dC-dA)n.(dG-dT)n polymorphisms. Genomics 1990, 7:524-530.

78. Wierdl M, Dominska M, Petes TD: Microsatellite instability in yeast: dependence on the length of the microsatellite. Genetics 1997, 146:769-779.

79. Nilsson NO, Hallden C, Hansen M, Hjerdin A, Säll T: Comparing the distribution of RAPD and RFLP markers in a high density linkage map of sugar beet. Genome 1997, 40:644-651.

80. Debener T, Mattiesch L: Construction of a genetic linkage map for roses using RAPD and AFLP markers. Theor Appl Genet 1999, 99:891-899.

81. Alonso Blanco C, Peters AJM, Korneef M, Lister C, Dean C, van den Bosch N, Pot J, Kuiper MTR: Development of an AFLP based linkage map of Ler, Col and Cvi Arabidopsis thaliana ecotypes and construction of a Ler/Cvi recombinant inbred line population. Plant J 1998, 14:259-271.

82. Chung SM, Staub JE, Chen JF: Molecular phylogeny of Cucumis species as revealed by consensus chloroplast SSR marker length and sequence variation. Genome 2006, 49:219-229.

83. Chen JF, Staub JE, Tashiro Y, Issiki S, Myiazaki S: Successful interspecific hybridization between Cucumis sativus L. and C. hystrix Chakr. Euphytica 1997, 96:413-419.

84. Chen JF, Staub J, Adelberg J, Lewis S, Kunkle B: Synthesis and preliminary characterization of a new species (amphidiploid) in Cucumis. Euphytica 2002, 123:3:15-322.
85. Chen JF, Luo XD, Qian CT, Molly MJ, Staub JE, Zhuang FY, Lou QF, Ren G: Cucumis monosomic alien addition lines: morphological, cytological, and genotypic analyses. Theor App/ Genet 2004, 108:1343-1348.

86. Koo DH, Nam YW, Choi D, Bang JW, de Jong H, Hur Y: Molecular cytogenetic mapping of Cucumis sativus and C. melo using highly repetitive DNA sequences. Chromosome Res 2010, 18:325-336.

87. Munger HM, Robinson RW: Nomenclature of Cucumis melo L. Cucurbit Genet Coop Rpt 1991, 14:43-44.

88. Luan F, Delannay I, Staub JE: Chinese melon (Cucumis melo L.) diversity analyses provide strategies for germplasm curation, genetic improvement, and evidentiary support of domestication patterns. Euphytica 2008, 164:445-461.

89. Zalapa JE, Staub JE, MCCreight JD, Chung SM, Cuevas H: Detection of QTL for yield-related traits using recombinant inbred lines derived from exotic and elite US Western Shipping melon germplasm. Theor Appl Genet 2007, 114:1185-1201.

90. Paris KM, Zalapa JE, McCreight JD, Staub JE: Genetic dissection of fruit quality components in melon (Cucumis melo L.) using a RIL population derived from exotic and elite US Western Shipping germplasm. Mol Breed 2008, 22:405-419.

91. Murray MG, Thompson WF: Rapid isolation of high molecular weight DNA. Nucleic Acids Res 1980, 8:4321-4325.

92. Weng Y, Li W, Devkota RN, Rudd JC: Microsatellite markers associated with two Aegilops tauschii-derived greenbug resistance loci in wheat. Theor Appl Genet 2005, 110:462-469.

93. Liu HB: Statistical Genomics: linkage, mapping and QTL analysis. CRC Press LLC, Boca Raton; 1998.

94. Qi X, Stam P, Lindhout P: Comparison and integration of four barley genetic maps. Genome 1996, 39:379-394.

doi:10.1186/1471-2164-12-396

Cite this article as: Li et al: Syntenic relationships between cucumber (Cucumis sativus L.) and melon (C. melo L.) chromosomes as revealed by comparative genetic mapping. BMC Genomics 2011 12:396.

\section{Submit your next manuscript to BioMed Central and take full advantage of:}

- Convenient online submission

- Thorough peer review

- No space constraints or color figure charges

- Immediate publication on acceptance

- Inclusion in PubMed, CAS, Scopus and Google Scholar

- Research which is freely available for redistribution 